\title{
Foreign body in vagina: a cause of persistent vaginal discharge in children
}

\author{
P. Pallavee ${ }^{1 *}$, Sunita Samal ${ }^{1}$, P. Sabita ${ }^{2}$
}

\begin{abstract}
${ }^{1}$ Department of Obstetrics \& Gynecology, Mahatma Gandhi Medical College \& Research Institute, Puducherry, India ${ }^{2}$ Department of Obstetrics \& Gynecology, Indira Gandhi Medical College and Research Institute, Puducherry, India
\end{abstract}

Received: 25 January 2013

Accepted: 22 March 2013

\section{*Correspondence:}

Dr. P. Pallavee,

E-mail: ppallavee@ rediffmail.com

(C) 2013 Pallavee $\mathrm{P}$ et al. This is an open-access article distributed under the terms of the Creative Commons Attribution License, which permits unrestricted use, distribution, and reproduction in any medium, provided the original work is properly cited.

\begin{abstract}
Vulvovaginitis and vaginal discharge in pediatric patients, while not uncommon, is commonly believed to be due to such causes as absence of the protective effect on the vaginal mucosa. However, other causes need also to be kept in mind. We report a case of chronic vaginal discharge in a $5 \mathrm{yr}$ old, who had retained a foreign body in her vagina for 6-7 months.
\end{abstract}

Keywords: Foreign body, Vagina, Children

\section{INTRODUCTION}

Chronic vaginal discharge in children is a relatively common gynecologic problem. The main predisposing factor is lack of protective effect of estrogen on vaginal mucosa. ${ }^{1}$ Other etiological factors include vulvar skin disease, sexual abuse, vaginal neoplasm and foreign bodies. $^{2}$ The presence of a foreign body should be suspected whenever a child presents with persistent or recurrent foul smelling discharge from vagina. Such foreign bodies may be inserted accidentally, or due to ignorance, malice, sexual stimulation or might even be manifestations of a psychosis. ${ }^{3}$ Young children also tend to explore all natural orifices and may place a variety of small objects in the vagina ${ }^{4}$. We present a case of a $5 \mathrm{yr}$ old girl with persistent vaginal discharge for 6 to 7 months not responding to any treatment.

\section{CASE REPORT}

A 5 yr old girl of low socio-economic status was referred from the pediatric outpatient department (OPD) to us, with complaints of foul smelling vaginal discharge for 6 to 7 months and burning micturition of 1 month duration.
She had been treated outside with repeated courses of antibiotics for vulvovaginitis without any significant response. On examination, she was of sound physical and mental health. Local examination revealed minimal excoriation around the vulva with foul smelling discharge from vagina. Per rectal examination could not be done as the child was uncooperative. Plain X-ray abdomen and pelvis and ultrasonography (USG) of the pelvis did not reveal any pathology. So, she was planned for examination under anesthesia (EUA) and vaginoscopy. On EUA, hymen was partially torn. On introduction of the nephroscope (vaginoscope was not available), a yellowish structure covered with flakes of pus was found in the vagina. It was removed by a small artery forceps and was found to be a groundnut with the shell intact. There was minimal erosion at the same place where it was lodged. Vagina was irrigated thoroughly with betadine solution, broad spectrum antibiotics were started and pus sent for culture and sensitivity workup. Vaginal discharge subsided completely within 3 days of initiating treatment and she was discharged after 5 days. The mother was counselled about possibility of sexual abuse and the need for psychiatric consultation if she was doing this on her own. 


\section{DISCUSSION}

In premenarchal girls under the age of $13 \mathrm{yrs}$, prevalence

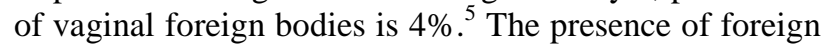
body in vagina for a long time can cause ulceration of vaginal walls, perforation, vesicovaginal fistula, vaginal stenosis and even complete obstruction of vagina. ${ }^{2} \mathrm{We}$ detected only minimal erosion of the vaginal walls.

The common foreign bodies recovered from vagina, as described in textbooks, are small pieces of toilet paper. ${ }^{4}$ Other common varieties include beads, safety pins, lead pencils, crayons, plastic stoppers, fibrous material from clothes and carpet. ${ }^{1}$ In our case it was a groundnut with the shell intact.

Diagnosis of a vaginal foreign body can be made by careful history taking, clinical examination, pelvic X-ray and USG or magnetic resonance imaging (MRI). Vaginoscopy or a $4 \mathrm{~mm}$ hysteroscope under general anesthesia (GA) or vaginal irrigation with normal saline are useful for detection and management.

The presence of a foreign body in children may be indicative of sexual abuse. Though this is not true always, the possibility should be kept in mind while treating. ${ }^{4}$ The child should also be assessed psychologically, because there may be underlying emotional and behavioural problems. 6

\section{CONCLUSION}

In case of children presenting with persistent purulent or bloody discharge per vaginum, unresponsive to general measures and medical therapy, the possibility of a vaginal foreign body should always be considered.

\section{REFERENCES}

1. Merkley K. Vulvovaginitis and vaginal discharge in the pediatric patient. J Emerg Nursing 2005;31:4002.

2. Deborah A, Simon BS, Berry S et al. Recurrent, purulent vaginal discharge with long standing presence of a foreign body and vaginal stenosis. J Pediatr Adolesc Gynecol 2003;16:361-3.

3. Wilcox RR, Wilcox JB. Venerological medicine. London: Grant McIntyre; 1982.

4. Adams PJ. Benign diseases of the female reproductive tract - symptoms and signs. In: Berek JS, editors. Novak's Gynecology. Philadelphia: Lippincott William Wilkins;2007.p.434-5.

5. Paradise JE, Willis ED. Probability of vaginal foreign body in girls with genital complaints. Am J Dis Child 1985;139:472-6.

6. Deliveliotou A. Vaginal foreign body in childhood. J Pediatr Child Health 2006;42:649-51.

DOI: $10.5455 / 2320-1770 . i j r \operatorname{cog} 20130624$

Cite this article as: Pallavee P, Samal S, Sabita P.

Foreign body in vagina: a cause of persistent vaginal discharge in children. Int J Reprod Contracept Obstet Gynecol 2013;2:224-5. 